\title{
Misuse and interlaboratory test reproducibility of API 20E system
}

\author{
B HOLMES, CA DAWSON
}

From the National Collection of Type Cultures, Central Public Health Laboratory, London

SUMMARY One hundred strains were referred to us for identification because they apparently could not be identified satisfactorily with the API 20E system (appareils et procédés d'identification). The inability to identify 31 strains was due primarily to failure to follow the manufacturer's instructions. Twenty six further strains were found to have been correctly identified by the sender's own API 20E results, so that only the remaining 43 strains definitely fell into the category for which our identification service was intended. Eighteen of the 43 strains not identified by the sender were identified by us using the API 20E system, and several possible reasons are given to explain the differences in these results. The remaining 25 strains either could not be identified by us on the API $20 \mathrm{E}$ system or, in the case of 13 , they could not be identified by our conventional system and therefore no comparison could be made. The average interlaboratory probability of errors for the API $20 \mathrm{E}$ tests was $6 \cdot 1 \%$.

The results of microbiological tests are not completely reproducible even when carefully repeated in a single laboratory..$^{-3}$ The variation is greater for results obtained from the same strains in different laboratories because of differences in media and methods for nominally identical tests. ${ }^{4}$ The best way of comparing the results of different studies of test reproducibility is to express them in terms of the estimated probabilities of erroneous test results.' Among laboratories the average probability of errors for conventional biochemical tests is typically $6-10 \%$, with probabilities of $20-30 \%$ for some tests; within one laboratory the probability of errors for such tests is $2-4 \%$ on average, with probabilities as high as $12 \%$ for some tests. ${ }^{34}$ Studies of the intralaboratory reproducibility of the tests in the API 20E system report that the estimated probability of erroneous test results is $1.6 \%$ over all the tests and $5 \%$ for the API citrate test. ${ }^{5}$ In a similar study the corresponding values were $2 \%$ and $6 \% .^{\circ}$

These overall values are low in comparison with the probabilities of $2-4 \%$ found in other studies using conventional tests. It was hoped that as commercial identification systems are produced and subjected to quality control at a central source they would also show improved interlaboratory test reproducibility approaching the level found within laboratories. There seems to have been only one

Accepted for publication 12 April 1985 previous study of interlaboratory test reproducibility of the API 20E system (but using strains of Bacillus). ${ }^{7}$ Factors affecting the reproducibility of the API 20E tests have been reported by Murray. ${ }^{8}$

The Computer Identification Laboratory of the National Collection of Type Cultures has, for many years, offered a service for the computer assisted identification of Gram negative bacteria that grow aerobically on nutrient agar. The strains referred are those that cannot be identified satisfactorily using the sending laboratory's identification system. Initially, the sending laboratories identified strains exclusively on conventional tests. Later, the API $20 \mathrm{E}$ system became used extensively, so a more satisfactory identification service for users of API $20 \mathrm{E}$ was devised.

The current practice is to provide us with a culture of the strain, together with the results that the sending laboratory obtained for it in the API 20E system. We re-examine the strain with API 20E and also identify it independently, with a computer assisted method that uses conventional tests. ${ }^{4}$ Consequently, our results obtained in the API $20 \mathrm{E}$ system can be compared with those obtained by the sender, and the identifications suggested by API $20 \mathrm{E}$ can also be compared with those obtained using our conventional system. We report here our experiences with a randomly selected but consecutive series of isolates received with the API $20 \mathrm{E}$ system results of the sender. 


\section{Material and methods}

\section{ORGANISMS}

During the study 813 strains were received for identification by our laboratory. Of these, 159 $(20 \%)$ were received with the senders' results having been obtained in the API $20 \mathrm{E}$ system. Of the 159 strains, $109(69 \%)$ were non-fermenters and 50 $(31 \%)$ were fermenters. Fifty of the 109 nonfermenters and all 50 fermenters were analysed in detail. The identity of each was determined on the results of conventional tests using a computer identification method. ${ }^{44}$

\section{TESTS AND PROCEDURES}

All the strains were examined in the API 20E system which consists of a strip of plastic cupules containing dehydrated media. These were inoculated with a suspension of the test organism in distilled water and incubated in accordance with the manufacturer's instructions. The API $20 \mathrm{E}$ tests were initially incubated for 24 hours, after which, if glucose was positive, the reagents were added and a profile number of seven digits constructed from the $21 \mathrm{API}$ $20 \mathrm{E}$ test results. If glucose was negative but three or more other reactions were positive then the foregoing procedure was again performed. If glucose was negative and no more than two other reactions were positive then the API $20 \mathrm{E}$ tests were reincubated for a further 24 hours. At the same time the following were also inoculated and incubated for 24 hours: a nutrient broth (in which to determine motility by the hanging drop technique), a MacConkey agar plate, and two tubes of $\mathrm{O}-\mathrm{F}$ medium (one to be sealed with liquid paraffin).

The next day, after the API 20E strip had been incubated for 48 hours, the reagents were added and the 21 test results recorded. In addition, reagents were added in the glucose tube to determine two further characters: reduction of nitrate to nitrite only and complete reduction of nitrate to nitrogen gas or amines. Four further characters were obtained from the tests incubated for only 24 hours: motility; growth on MacConkey agar; acid in the oxidative tube of $\mathrm{O}-\mathrm{F}$ medium $(+$ or -$)$; and acid in the fermentative tube of $\mathrm{O}-\mathrm{F}$ medium $(+$ or - ) (for a fermentative organism acid is produced in both tubes so a "+" is recorded for both tests). A profile number of nine digits could then be constructed from the 27 test results.

\section{IDENTIFICATION OF STRAINS}

In the API $20 \mathrm{E}$ system identification is obtained by an exact match of the results of an unknown strain against a named pattern held in a register in the form of a numerical code (profile number). ${ }^{10}$ The manufacturer refers to the register as the profile index and ours was dated April 1978. Patterns of test results not listed in the profile index were submitted to the complementary API Computer Identification Service (using a copy held on our computer). For some identifications additional conventional tests, as well as serological investigations, may be required to further or confirm the identification. The additional tests were not usually performed in this study; if the system indicated the correct taxon as one of the possible identities then this was counted as a correct identification. If serological investigation was necessary to prevent a misidentification then that pattern of results was counted as not identified.

\section{Results}

Strains requiring incubation for 24 hours (21 test results) are generally fermenters while those requiring 48 hours (27 test results) are generally nonfermenters. Table 1 shows how the API 20E system had been used and misused in some sending laboratories with respect to the number of tests performed and the period of incubation for both these groups of organisms.

Interlaboratory test reproducibility was determined only for the 69 strains that had definitely been examined in accordance with the manufacturer's instructions; tables 2 and 3 show these results.

Table 4 summarises the identification of strains from the senders' API $20 \mathrm{E}$ results, our API $20 \mathrm{E}$ results, and those obtained from our conventional system.

\section{Discussion}

The API 20E system was designed specifically for the identification of Enterobacteriaceae, so that identification of fermenters with the system would be straightforward. Of the 50 fermentative strains, however, 14 were definitely not examined in the API 20E kit according to the manufacturer's instructions and two more possibly fall into this category (table 1). In addition, some of the nine strains incubated for 48 hours by the sender but found by us to require incubation for only 24 hours may have been incorrectly incubated by the sender for longer than necessary. The senders' results could be used for only 34 of the 50 strains.

The API 20E system was extended to include non-fermenters by the addition of six supplementary tests and prolonged incubation of the API $20 \mathrm{E}$ tests. For at least 12 and possibly three more of the 50 non-fermentative strains, however, the main reason 
Table 1 Use and misuse of the API 20E system

\begin{tabular}{|c|c|c|c|c|}
\hline \multirow[t]{2}{*}{ Errors in use } & \multicolumn{3}{|c|}{ Period of incubation used by sender } & \multirow[t]{2}{*}{ Comment } \\
\hline & 24 hours & 48 hours & Not stated & \\
\hline $\begin{array}{l}\text { Fermenter strains }(50) \\
\text { Incubation of only } 24 \text { hours required } \\
\text { Errors: }\end{array}$ & 19 & 14 & 17 & \\
\hline Oxidase omitted & 2 & & & $\begin{array}{l}\text { Profile number of seven digits } \\
\text { unobtainable }\end{array}$ \\
\hline $\begin{array}{l}\text { Incubation of } 48 \text { hours required } \\
\text { Not all six supplementary tests } \\
\text { performed }\end{array}$ & 1 & 6 & 2 & $\begin{array}{l}\text { Profile number of seven digits invalid } \\
\text { Profile number of nine digits } \\
\text { unobtainable }\end{array}$ \\
\hline $\begin{array}{l}\text { Incubation of } 48 \text { hours required and } \\
\text { not all six supplementary tests } \\
\text { performed }\end{array}$ & & & 2 & $\begin{array}{l}\text { Profile number of nine digits } \\
\text { unobtainable }\end{array}$ \\
\hline $\begin{array}{l}\text { Incomplete recording of API } 20 \mathrm{E} \\
\text { results }\end{array}$ & & & 3 & No profile number obtainable \\
\hline $\begin{array}{l}\text { No correctly examined: } \\
\text { Non-fermenter strains }(50) \\
\text { Incubation of } 48 \text { hours required } \\
\text { Errors: }\end{array}$ & $\begin{array}{l}16 \\
16 \\
12^{*}\end{array}$ & $\begin{array}{r}8 \\
13\end{array}$ & $\begin{array}{l}10 \\
21\end{array}$ & Total 34 \\
\hline Incubation of 48 hours required & 1 & & & $\begin{array}{l}\text { Profile number of nine digits } \\
\text { unobtainable }\end{array}$ \\
\hline $\begin{array}{l}\text { Not all six supplementary } \\
\text { tests performed }\end{array}$ & & 6 & 2 & $\begin{array}{l}\text { Profile number of nine digits } \\
\text { unobtainable }\end{array}$ \\
\hline $\begin{array}{l}\text { Incubation of } 48 \text { hours required and } \\
\text { not all six supplementary tests } \\
\text { performed }\end{array}$ & 5 & & 1 & $\begin{array}{l}\text { Profile number of nine digits } \\
\text { unobtainable }\end{array}$ \\
\hline No correctly examined & 10 & 7 & 18 & $\begin{array}{l}\text { Total } 35 \\
\text { Total correctly examined } 69\end{array}$ \\
\hline
\end{tabular}

* These figures relate to the period of incubation that we found necessary. The sender was not necessarily in error to use a different period of incubation, so these figures should be regarded as comments, rather than errors; they are not included in the subtotals.

for the failure of the sender to identify the strain in his own laboratory was a failure to follow the manufacturer's instructions about the period of incubation or the performance of supplementary tests, or both (Table 1). A profile number of nine digits could not be derived nor could an identification be attempted from the senders' results for any of these 15

Table 2 Number of test differences per strain

\begin{tabular}{ll}
\hline No of test differences & No of strains (No of differences) \\
\hline 0 & 7 \\
1 & 14 \\
2 & $14(3)$ \\
3 & $14(5)$ \\
4 & $7(2)$ \\
5 & $8(2)$ \\
6 & $1(1)^{*}$ \\
7 & $2(1)$ \\
8 & $1(1)$ \\
9 & 1 \\
10 & 0 \\
\hline Total & $69 \dagger$ \\
\hline
\end{tabular}

Numbers in parentheses indicate number of strains in which there was, or may have been, a difference in the period of incubation. These figures include oxidase and the supplementary tests.

* In this strain there was also a difference in inoculating medium that may have been responsible for the test differences.

†For 31 of the 100 strains no comparison of test differences was made because not all required tests had been performed by the sender. strains. These strains were also excluded from the assessment of test reproducibility. The senders' results could be used for only 35 of the 50 strains and even in 18 of these an incubation period of 48 hours had to be assumed (in three of these strains, however, we found that only an incubation of 24 hours was necessary).

Of all the 100 strains, only 69 had definitely been examined properly in the API 20E system in accordance with the manufacturer's instructions. Interestingly, the number of improperly examined strains was almost the same for fermenters as for nonfermenters. A higher rate would have been expected for non-fermenters which generally require extended incubation and supplementary tests. Our own evaluation of the API $20 \mathrm{E}$ system for the identification of Enterobacteriaceae showed the product to be accurate with only a low probability of misidentification" (we did not evaluate this product for the identification of non-fermenters).

Our findings are worrying as clearly, several people are failing to obtain an identification on the product through misuse of the system. Possibly, our observations are merely a small proportion of the total number of such misuses. If the problem is indeed more common then probably some of the identifications obtained from the system (which we therefore do not see) are misidentifications. We 
Table 3 No of differences observed for each test (62 strains analysed)

\begin{tabular}{|c|c|c|c|}
\hline Test & $\begin{array}{l}\text { No of } \\
\text { differences }\end{array}$ & Test & $\begin{array}{l}\text { No of } \\
\text { differences }\end{array}$ \\
\hline \multirow{13}{*}{$\begin{array}{l}\text { ONPG (BD galactosidase production) } \\
\text { Arginine dihydrolase } \\
\text { Lysine decarboxylase } \\
\text { Ornithine decarboxylase } \\
\text { Use of citrate } \\
\text { Production of hydrogen sulphide } \\
\text { Production of urease } \\
\text { Production of tryptophane deaminase } \\
\text { Production of indole } \\
\text { Production of acetoin } \\
\text { Production of gelatinase } \\
\text { Acid from: } \\
\text { Glucose }\end{array}$} & 11 & Inositol & 4 \\
\hline & 8 & Sorbitol & 6 \\
\hline & 5 & Rhamnose & 6 \\
\hline & 9 & Sucrose & 7 \\
\hline & 11 & Melibiose & 12 \\
\hline & 1 & Amygdalin & 6 \\
\hline & 8 & Arabinose & 17 \\
\hline & 6 & Production of oxidase* & 7 \\
\hline & 4 & & \\
\hline & 9 & Reduction of nitrate* & 9 \\
\hline & 7 & Reduction of nitrite* & 8 \\
\hline & & Motility* & 2 \\
\hline & 12 & Growth on MacConkey agar* & 2 \\
\hline Mannitol & 5 & $\begin{array}{l}\text { Acid in open O-F tube* } \\
\text { Acid in sealed O-F tube }\end{array}$ & $\begin{array}{l}6 \\
1\end{array}$ \\
\hline
\end{tabular}

${ }^{*}$ Differences in the oxidase and supplementary tests are included because of their effects on identification rates. As they may be determined by conventional methods and the supplementary tests are not performed on every strain, they are not included in the calculations of test reproducibility.

hope that the strains we examine represent a small proportion of those tested with API $20 \mathrm{E}$, and most are identified correctly.

API has recently introduced a new product (API 20NE) specifically designed for the identification of organisms positive for oxidase (non-fermenters, Pasteurellaceae, and Vibrionaceae). As this product gains acceptance we may see fewer misuses of the API $20 \mathrm{E}$ system currently associated with nonfermenters-namely, failure to incubate for 48 hours or failure to perform all six supplementary tests, or both; doubtless, misuses of the API 20NE system will continue to occur. We have already identified a strain of Escherichia coli which the sender had tried to identify using API 20NE. No doubt, many laboratories will prefer to continue using a single product for both fermenters and non-fermenters and will therefore use only API $20 \mathrm{E}$. For the future it is to be hoped that the development of API s new 32GN gallery, for use on the API ATB automated system, may resolve some of the above problems, but it is not certain if this product will ever be marketed in the United Kingdom. Certainly, with the $32 \mathrm{GN}$ gallery the same (assimilation) tests are used for both fermenters and non-fermenters, and it is to be hoped that the period of incubation can be made more or less the same for both groups of organisms and that fewer occasions will arise when supplementary tests need to be performed.

Some of the differences in tests observed between us and the sender can be attributed to a difference in the period of incubation that we and the sender used (Table 2). In one strain, a Vibrio, there was also a difference in inoculating medium (distilled water $v$ saline). Nevertheless, the number of differences in tests observed for such a standardised product was surprising. It can be seen from Table 3 that the reproducibility was worst for production of acid from arabinose, where discrepancies are probably the result of weaker reactions being obtained with this carbohydrate than with the other carbohydrates on the API 20E strip.

The average probability of errors over all the 20 API $20 \mathrm{E}$ tests was $6.1 \%$ (and for the API citrate test $8.7 \%$ ). The figure of $6.1 \%$ was higher than the corresponding values reported in studies of intralaboratory test reproducibility using the API $20 \mathrm{E}$ system; ${ }^{56}$ although the value was outside the range for intralaboratory test reproducibility using

Table 4 Identification of strains using API 20E system

\begin{tabular}{|c|c|c|c|}
\hline \multicolumn{3}{|l|}{ Identification correct } & \multirow[t]{2}{*}{ No of strains $(n=69)$} \\
\hline Sender's API $20 E$ results & NCTC API $20 E$ results & NCTC conventional system & \\
\hline $\begin{array}{l}+ \\
+ \\
\mathrm{NC} \\
- \\
-\end{array}$ & $\begin{array}{l}+ \\
- \\
\mathrm{NC} \\
- \\
+\end{array}$ & $\begin{array}{l}+ \\
+ \\
+ \\
+ \\
+\end{array}$ & $\begin{array}{r}25 \\
1 \\
13 \\
12 \\
18\end{array}$ \\
\hline
\end{tabular}

$\mathrm{NC}=$ No comparison made. 
conventional tests, it was at the lower end of the range for interlaboratory reproducibility of conventional tests. ${ }^{34}$ The interlaboratory reproducibility of the API 20E system was thus not as high as it might have been for a standardised product, presumably owing to factors such as the need for a standardised inoculum, as discussed by Murray. ${ }^{8}$ Interestingly, although previous studies had identified citrate as the test with lowest intralaboratory reproducibility, ${ }^{56}$ between laboratories other tests fared even worse in this study - namely, arabinose, glucose, and melibiose.

The results presented above were derived from strains that were, by definition, problems, otherwise they would not have been sent to us. It may therefore be considered unfair to compare our data on reproducibility with those previously published for the API 20E system and conventional tests, where randomly selected strains were used. The interlaboratory reproducibility of the API $20 \mathrm{E}$ system might have been higher had we tested 69 randomly selected strains instead. If this is so, however, it should apply primarily to those strains for which differences in test results between us and the sender proved to be the main reason for the sender failing to identify the strain in his own laboratory, which applies to only 18 of 69 strains in our study.

Although in 13 of the strains a satisfactory identification could not be obtained using the conventional system (Table 4), there was generally close agreement between our system and the API 20E. For example, one strain identified as an Enterobacter cloacae on both the sender's and our API 20E results seemed to be most probably an atypical $E$ cloacae on our conventional system. For another strain, which could not be identified on the sender's results, we obtained a very good identification of Pseudomonas cepacia on our results in the API 20E system; on our conventional system this strain seemed to be an atypical $\boldsymbol{P}$ cepacia. In other cases we could identify the strain successfully to the level of genus on our conventional system, and this generally agreed with the likely taxa suggested by the API $20 \mathrm{E}$ system. For some of the strains not identified by our conventional system an identification was obtained on the sender's or our API $20 \mathrm{E}$ results, or both that was not in general agreement with the taxa suggested by our conventional system. Eighteen strains were identified satisfactorily on our API 20E results but not on those of the sender.

There are several possible reasons for the observed differences in test results for these strains between ourselves and the sender, including differences in interpretation. Where more than one or two differences in tests were observed, however, the fol- lowing explanations may be more likely: the sender may test one strain but refer another that has been derived from a separate but morphologically similar colony, he may test a contaminated culture and obtain false positive results; or he may test a strain that has been inhibited either by treatment with antibiotics or by disinfectant or other residues present on laboratory glassware, so that by the time the strain reaches us it has probably recovered and produces typical results. Where differences between us and the sender were noted we assumed that we were correct. Though this probably holds true, we did note one exception where a strain was identified on the sender's API 20E results (although only to the level of genus) that agreed with the identification suggested by our conventional system; using the results from our API 20E, however, the strain was not identified even to the correct genus (Table 4).

As we examined a consecutive number of strains we sometimes examined several strains received at the same time from a single laboratory. This will have distorted our figures according to the efficacy of the laboratory in using the API 20E system.

We thank PS Humphry for technical help.

\section{References}

' Sneath PHA. Johnson R. The influence on numerical taxonomic similarities of errors in microbiological tests. J Gen Microbiol 1972; 72:377-92.

${ }^{2}$ Snell JJS, Lapage SP. Carbon source utilisation tests as an aid to the classification of non-fermenting Gram-negative bacteria. $J$ Gen Microbiol 1973;74:9-20.

${ }^{3}$ Sneath PHA. Test reproducibility in relation to identification. International Journal of Systematic Bacteriology 1974; 24: 508-23.

4 Lapage SP, Bascomb S, Willcox WR, Curtis MA. Identification of bacteria by computer: general aspects and perspectives. $J$ Gen Microbiol 1973; 77:273-90.

s Holmes B, Willcox WR, Lapage SP, Malnick H. Test reproducibility of the API (20E), enterotube, and pathotec systems. J Clin Pathol 1977;30:381-7.

- Butler DA, Lobregat CM, Gavan TL. Reproducibility of the analytab (API 20E) system. J Clin Microbiol 1975;2:322-6.

' Logan NA, Berkeley RCW, Norris JR. Results of an international reproducibility trial using the API system applied to the genus Bacillus. J Appl Bacteriol 1978;45:28-9.

${ }^{8}$ Murray PR. Standardisation of the analytab enteric (API 20E) system to increase accuracy and reproducibility of the test for biotype characterisation of bacteria. J Clin Microbiol 1978;8:46-9.

' Willcox WR, Lapage SP, Holmes B. A review of numerical methods in bacterial identification. Antonie van Leeuwenhoek 1980;46: 233-99.

${ }^{10}$ D' Amato RF, Holmes B, Bottone EJ. The systems approach to diagnostic microbiology. CRC Crit Rev Microbiol 1981;9: $1-44$.

" Holmes B, Willcox WR, Lapage SP. Identification of Enterobacteriaceae by the API 20E system. J Clin Pathol 1978;31: 22-30.

Requests for reprints to: Mr B Holmes, NCTC, Central Public Health Laboratory, 61 Colindale Avenue, London NW9 5HT, England. 